\title{
Dynamics of quality of life improvement after floppy Nissen fundoplication for gastroesophageal reflux disease
}

\author{
Jarek Kobiela ${ }^{1}$, Łukasz Kaska ${ }^{1}$, Magdalena Pindel $^{1}$, Arkadiusz Szarmach $^{2}$, Maria Janiak $^{3}$, \\ Monika Proczko-Markuszewska ${ }^{1}$, Tomasz Stefaniak ${ }^{1}$, Dariusz Łaski ${ }^{1}$, Andrzej Łachiński ${ }^{1}$, Zbigniew Śledziński ${ }^{1}$ \\ ${ }^{1}$ Department of General, Endocrine and Transplant Surgery, Medical University of Gdansk, Gdansk, Poland \\ 2Department of Radiology, Institute of Radiology and Nuclear Medicine, Medical University of Gdansk, Gdansk, Poland \\ ${ }^{3}$ Department of Gastroenterology and Hepatology, Medical University of Gdansk, Gdansk, Poland
}

Videosurgery Miniinv 2015; 10 (3): 389-397

DOI: $10.5114 /$ wiitm.2015.54187

\begin{abstract}
Introduction: Gastroesophageal reflux disease (GERD) has a negative impact on global quality of life (QOL) of patients. In patients affected by GERD, laparoscopic Nissen fundoplication is one of the most commonly performed laparoscopic procedures worldwide.

Aim: To prospectively analyze the dynamics of QOL as well as severity of pain in patients with GERD, before and after laparoscopic floppy Nissen fundoplication.

Material and methods: The study involved 104 consecutive patients operated on for GERD in whom laparoscopic floppy Nissen fundoplication was performed. QOL was assessed before surgery and 1, 3, 6, 12 and 24 months after. The following instruments were used: FACIT-G, FACIT-TS-G, GIQLI, GERD symptom scale.

Results: It was found that symptom relief and quality of life improvement presented different dynamics in the postoperative course. Observations revealed relief of symptoms 1 month after surgery and improvement in QOL related to the gastrointestinal tract and pain 3 months after surgery. Global QOL increased significantly as late as 12 months after surgery.

Conclusions: Gastroesophageal reflux disease is a chronic disease of long duration, leading to impairment of quality of life. Patients, apart from typical symptoms of GERD, suffer from pain of significant severity. QOL improves significantly after surgery. Surgical treatment results in relief of GERD symptoms, which leads to gradual improvement of QOL.
\end{abstract}

Key words: quality of life, gastroesophageal reflux disease, Nissen fundoplication.

\section{Introduction}

Gastroesophageal reflux disease (GERD) is a chronic, recurrent disease commonly recognized in developed countries. The disease manifests itself with varying severity, from mild to incapacitating, with significant impairment of quality of life [1]. For this reason, quality of life assessments are commonly used in conjunction with objective examinations in the evaluation of a treatment's efficacy relating to this disease [2]. Interestingly, to a significant extent, the results of objective examinations are not always aligned with patient functioning, general well-being and treatment satisfaction [3]. Despite a technically correct procedure and satisfactory objective examinations, some patients report a subpar outcome [3]. Different authors have suspected different potential backgrounds to the latter phenomenon. Most pertain to the preoperative psychological status of the patient (e.g. depression) as being co-responsible

\section{Address for correspondence}

Jarek Kobiela MD, PhD, Department of General, Endocrine and Transplant Surgery, Medical University of Gdansk,

17 Smoluchowskiego St, 80-2011 Gdansk, Poland, phone: +48 503114 069, e-mail: kobiela@gumed.edu.pl 
for postoperative dissatisfaction with treatment [4] Therefore, quality of life assessment seems a valuable tool for outcome evaluation in GERD. It is worth mentioning that quality of life impairment due to GERD is more extensive than, for instance, due to diabetes, arterial hypertension or following myocardial infarction [2].

Surgical treatment of GERD was widely introduced with the development of the laparoscopic approach, and the first laparoscopic anti-reflux procedure was performed in 1991 by Geagea [5]. In several upper GI centers laparoscopic floppy Nissen fundoplication has been widely accepted as a gold standard [6]. It has also been indicated as a first choice surgical treatment in the guidelines of both the European Association for Endoscopic Surgery and the Society of Gastrointestinal and Endoscopic Surgery [7, 8].

Typical symptoms of GERD are heartburn, regurgitation and dysphagia. One of the most commonly omitted symptoms during history taking is epigastric pain.

\section{Aim}

The aim of the study was to evaluate the dynamics of quality of life improvement after laparoscopic floppy Nissen fundoplication. The dynamics evaluated were the time sequence of symptom relief and improvement of quality of life. Moreover, it was aimed to assess severity of pain in patients suffering from GERD before and after laparoscopic floppy Nissen fundoplication.

\section{Material and methods}

\section{Material}

A data group of 104 consecutive patients with documented GERD who underwent operations between January 2004 and June 2008 in the Department of General, Endocrine and Transplant Surgery, Medical University of Gdansk, was prospectively analyzed. The study group consisted of 66 men and 38 women. Average age was 49 years (range: 23-75 years). In all patients laparoscopic floppy Nissen fundoplication was performed. Mesh repair was considered an exclusion criterion. The operating surgeons could be characterized as expert laparoscopists (with over 80 laparoscopic anti-reflux procedures performed each). The study was approved by the Local Independent Bioethical Committee at the Medical University of Gdansk.

\section{Surgery and postoperative course}

The surgical procedure was performed in a standard manner, with liberation of the gastrosplenic ligament with LigaSure. Fundoplication was calibrated on a $10 \mathrm{~mm}$ laparoscopic Babcock placed as a probe between the stomach wall and fundoplication ring. Operating time did not exceed $150 \mathrm{~min}$, with an average time of $62 \mathrm{~min}$.

In the group of 104 patients, 32 complications or medical events were noted in a total of 21 patients. Seven patients were re-evaluated due to lack of improvement or symptom recurrence; of those aforementioned individuals, four underwent revision surgery. Fourteen patients presented to the emergency room because of dysphagia during the first 8 weeks following the operation. Twelve cases were successfully treated symptomatically. Two cases required endoscopic ballooning, which was performed with success. In 6 patients, $\mathrm{CO}_{2}$ subcutaneous emphysema or pneumothorax was observed, but lacked clinical significance. Umbilical port site infection was observed in four patients; umbilical hernia occurred in one of them.

\section{Quality of life}

Intensity of epigastric pain was analyzed at all follow-up meetings using the Visual Analogue Scale (VAS). The VAS is a scale ranging from 0 to 10 , with 10 representing the highest imaginable pain and 0 representing no pain at all. Quality of life assessments were performed directly by a medical doctor in an outpatient clinic preoperatively as well as 1,3 , 6, 12 and 24 months after surgery. Quality of life was assessed using three questionnaires:

- Functional Assessment of Chronic Illness Therapy, FACIT-G - a 27-item Likert scale (scored with 0-108 points) intended for assessment of general health-related quality of life $[9,10]$. It consists of four subscales: physical functioning, social and family functioning, emotional functioning, everyday functioning. FACIT-TS-G (treatment satisfaction - general) is an eight-item Likert scale scored with 0-25 points designed for evaluation of patient satisfaction with treatment. Results of FACIT-G and FACIT-TS-G were represented as a percentage of the highest possible score (0-100\%).

- Gastrointestinal Quality of Life Index (GIQLI) recommended by the European Study Group for Antireflux Surgery for evaluation of quality of life related to gastrointestinal disease [11]. GIQLI, 
a 36-item Likert scale, constitutes of five subscales: gastrointestinal symptoms, emotional status, physical functioning, social functioning and a single item that aims to assess treatment satisfaction. Scores range from 0 to 144 points.

- DeMeester and Johnson GERD symptom scale a three-item Likert questionnaire assessing the main symptoms of GERD during the previous month, those symptoms being heartburn, regurgitation and dysphagia [12]. Each symptom is scored from 0 to 3 points, corresponding to its severity. The total result may range from 0 to 9 points.

Duration of the disease was on average 6.54 \pm 7.96 years with duration of pain being $4.89 \pm 6.09$ years. Return to full activity was observed, on average, in 8.21 weeks and resumption of work occurred after an average of 5.07 weeks. Follow-up efficiency was reported: at 1 month $-89.42 \%, 3$ months - 80.69\%, 6 months - 74.04\%, 12 months $-68.27 \%$, 24 months $-53.85 \%$. At 24 months after surgery, 14 patients (25\%) reported occasional use of antisecretory drugs with the mode value of one tablet per day.

\section{Statistical analysis}

Statistical analysis was performed with Statistica 7.1 PL software. ANOVA and Fisher's post-hoc tests were used. Statistical significance was achieved when $p$ value was less than 0.05 .

\section{Results}

Pain

The average pain score prior to surgical intervention, evaluated via the VAS scale, was $6.3 \pm 3.36$ points. A statistically significant decrease of pain (40\% reduction of preoperative values) was observed 3 months after surgery (Table I).

\section{Symptom relief and quality of life}

Gastroesophageal reflux disease symptoms, measured with the DeMeester and Johnson scale, improved significantly in the first month following surgery and remained at this level until 24 months after surgery (Figure 1).

More specifically, a notable improvement of heartburn and regurgitation could be observed 1 month after surgery. At 1 month following the surgical procedure, that is within the first post-operative follow-up period, a marked increase of dysphagia (de novo) was noticed (Table II).

Significant improvement in gastrointestinal quality of life (GIQLI) was found 3 months after surgery and remained at that level through the next 24 months (Figure 2). Significant improvement was observed at different points in time within all sub-scales. The main sub-scales responsible for notable enhancement of gastrointestinal quality of life were gastrointestinal symptoms and emotional status (Table III).

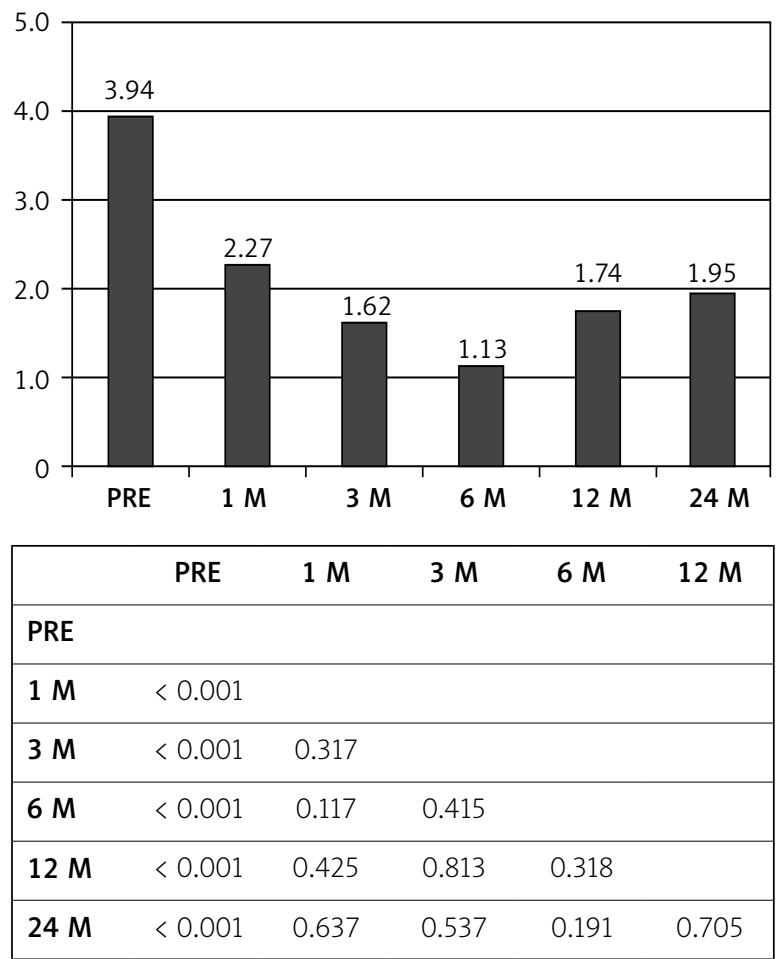

Figure 1. Total score in DeMeester and Johnson GERD symptom scale. ANOVA $p<0.001$. Posthoc $p$ values given in table below graph

Table I. Pain at follow-up points. Shaded values represent significant differences compared to preoperative assessment in post-hoc analysis

\begin{tabular}{|lccccccc|}
\hline & PRE & $1 M$ & $3 M$ & $6 M$ & $12 M$ & $24 M$ & ANOVA \\
\hline Pain & 6.34 & 6.03 & 3.84 & 4.08 & 4.19 & 4.31 & $p<0.001$ \\
\hline
\end{tabular}


Table II. Three symptoms evaluated with the DeMeester and Johnson GERD symptom scale at follow-up points. Shaded values represent significant differences compared to preoperative assessment in post-hoc analysis

\begin{tabular}{|llllllll|}
\hline Symptoms & PRE & $1 M$ & $3 M$ & $6 M$ & $12 M$ & $24 M$ & ANOVA \\
\hline Heartburn & 1.94 & 0.64 & 0.52 & 0.47 & 0.48 & 0.80 & $p<0.001$ \\
\hline Regurgitation & 1.50 & 0.27 & 0.44 & 0.27 & 0.57 & 0.55 & $p<0.001$ \\
\hline Dysphagia & 0.48 & 1.36 & 0.52 & 0.40 & 0.70 & 0.60 & $p<0.001$ \\
\hline
\end{tabular}

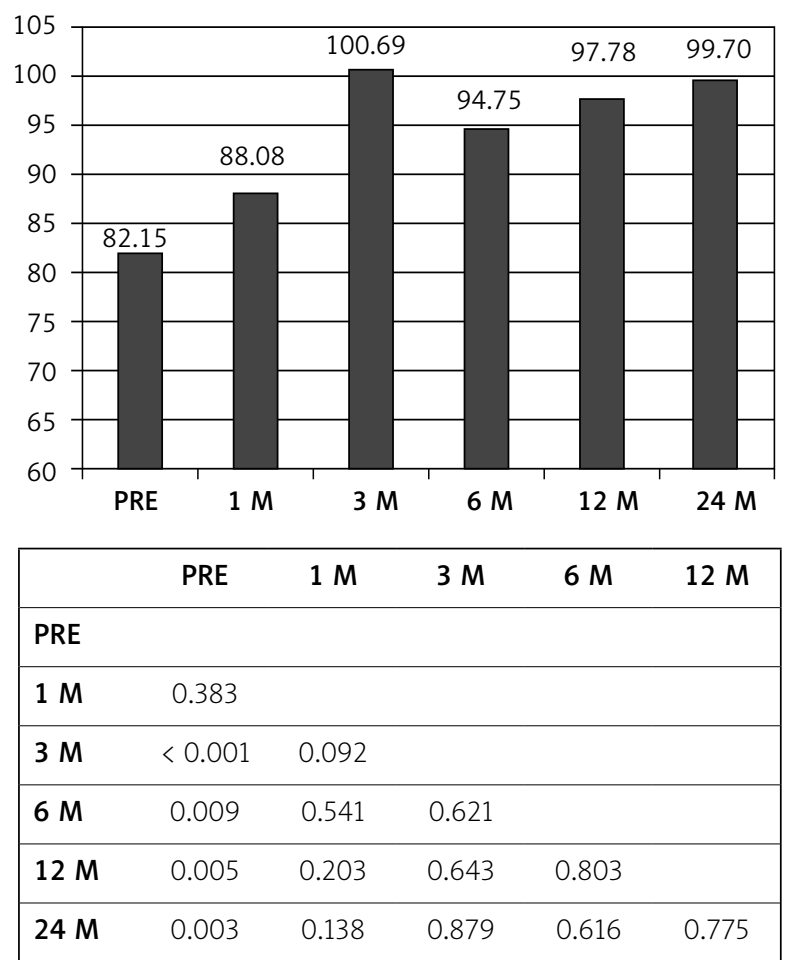

Figure 2. Total gastrointestinal quality of life (GIQLI) score. ANOVA $p=0.002$. Post-hoc $p$ values presented in table below graph

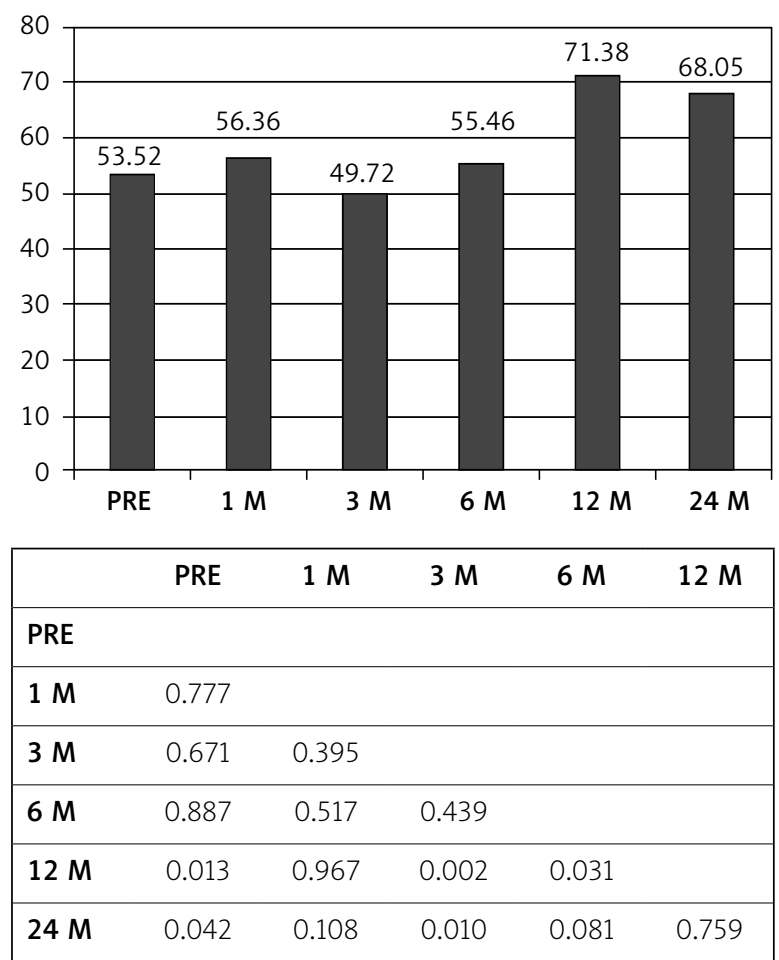

Figure 3. Total FACIT-G score. ANOVA $p=0.005$. Post-hoc $p$ values given in table below graph

Table III. Results in sub-scales of GIQLI. Shaded values represent significant differences compared to preoperative assessment in post-hoc analysis

\begin{tabular}{|lccccccc|}
\hline Sub-scales & PRE & $1 M$ & $3 M$ & $6 M$ & $12 M$ & $24 M$ & ANOVA \\
\hline Gl symptoms & 40.78 & 45.58 & 54.00 & 49.93 & 49.74 & 50.65 & $p=0.001$ \\
\hline $\begin{array}{l}\text { Physical } \\
\text { functioning }\end{array}$ & 14.32 & 16.50 & 16.23 & 16.67 & 17.57 & 17.95 & $p=0.021$ \\
\hline $\begin{array}{l}\text { Social } \\
\text { functioning }\end{array}$ & 10.70 & 10.92 & 13.08 & 12.33 & 13.17 & 12.20 & $p=0.034$ \\
\hline $\begin{array}{l}\text { Emotional } \\
\text { status }\end{array}$ & 10.49 & 11.33 & 14.58 & 12.93 & 14.39 & 15.65 & $p<0.001$ \\
\hline $\begin{array}{l}\text { Treatment } \\
\text { satisfaction }\end{array}$ & 2.51 & 2.75 & 2.92 & 3.00 & 3.26 & 3.25 & $p=0.021$ \\
\hline
\end{tabular}


Table IV. Results in sub-scales of FACIT-G. Shaded values represent significant differences compared to preoperative assessment in post-hoc analysis

\begin{tabular}{|lccccccc|}
\hline Sub-scales & PRE & $1 \mathrm{M}$ & $3 \mathrm{M}$ & $6 \mathrm{M}$ & $12 \mathrm{M}$ & $24 \mathrm{M}$ & ANOVA \\
\hline $\begin{array}{l}\text { Physical } \\
\text { functioning }\end{array}$ & 53.11 & 74.57 & 66.07 & 68.65 & 74.76 & 72.73 & $p=0.018$ \\
\hline $\begin{array}{l}\text { Everyday } \\
\text { functioning }\end{array}$ & 54.47 & 78.57 & 68.45 & 64.29 & 75.71 & 72.40 & $p=0.037$ \\
\hline $\begin{array}{l}\text { Social and } \\
\text { family } \\
\text { functioning }\end{array}$ & 75.28 & 70.97 & 79.72 & 69.41 & 76.09 & 75.53 & $p=0.779$ \\
\hline $\begin{array}{l}\text { Emotional } \\
\text { functioning }\end{array}$ & 60.61 & 62.50 & 71.88 & 69.22 & 72.30 & 68.98 & $p=0.327$ \\
\hline
\end{tabular}

Global quality of life measured with the FACIT-G questionnaire improved significantly 12 months after surgery (Figure 3). The sub-scales chiefly responsible for significant improvement within FACIT-G were physical functioning and everyday functioning (Table IV).

Overall satisfaction with surgical treatment was high and did not change significantly during the observation period (Figure 4).

\section{Discussion}

In this study we found that GERD is associated with significant epigastric pain and that quality of life improves significantly following laparoscopic floppy Nissen fundoplication. Moreover, we demonstrated that the dynamics of quality of life improvement are different for different aspects of quality of life.

Epigastric pain was observed in virtually all patients $(92.31 \%)$ prior to surgery, and the duration of the pain was on average nearly 5 years. Pain in the epigastrium prior to surgery was scored with an average value of 6.34 on the VAS scale, which, according to the Kelly classification, is of moderate severity [13]. Omission of this category and location of pain is not an uncommon practice in medical workups of patients with GERD. As mentioned in prior statements, surgical treatment with laparoscopic floppy Nissen fundoplication led to pain relief 3 months after the procedure. Upon the follow-up visit 1 month after surgery, it was found that pain remained at the level observed before the surgical procedure. This phenomenon is most likely a result of relief from GERD-associated discomfort in combination with increased epigastric pain related directly to the surgery itself. Abdominal pain and chest pain

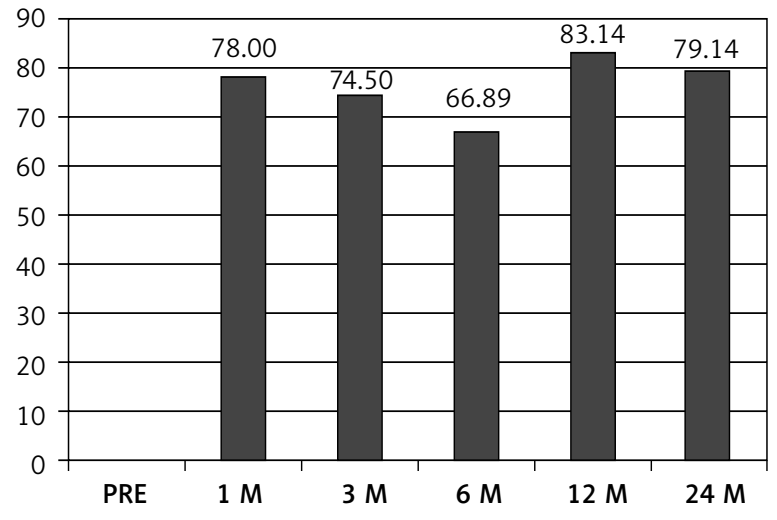

Figure 4. FACIT-TS-G score at follow-up points. ANOVA $p=0.531$. Post-hoc analysis - no significant differences. By definition treatment satisfaction was not measured before surgery

following laparoscopic fundoplication are reported in $24.0 \%$ and $19.5 \%$ of patients respectively. Pain was mild or moderate in the majority and severe in $4 \%$ of patients. Neither frequency nor severity of pain was associated with operation type [14].

The possible role of central sensitization in delayed pain relief should be recognized [15]. That is, hypersensitivity of the hypothalamus and cortex, caused by pain related to GERD in the preoperative period, can lead to misinterpretation of the stimuli in this region or aggravation of mild pain [16]. Pain significantly decreases 3 months after surgery. At this follow-up point, relief of de novo dysphagia and improvement in gastrointestinal quality of life are also observed. These observations support our explanation based on the adjustment to changed hiatal anatomy.

Average duration of the disease was 6.54 years, similarly to that observed in other studies $[17,18]$. 
Long duration of the illness and unsuccessful medical treatment in this group of patients can lead to psychological changes typical for chronic diseases [19]. These changes are described in relation to several diseases such as rheumatoid diseases, psoriasis, chronic renal failure, asthma, chronic pancreatic pain, hyperhydrosis or obesity [20]. Patients suffering from chronic ailments learn to live with the disease, and an immediate recovery, such as that witnessed with anti-reflux surgery, can paradoxically cause stress and engage new adaptation mechanisms. This, in and of itself, holds the possibility of impairment of quality of life [19].

The preoperative average for the DeMeester and Johnson score was 3.94 points (on a scale from 0 to 9). Laparoscopic Nissen fundoplication leads to significant improvement in this symptom score as early as 1 month after surgery, an effect which remains throughout the observational period. The main symptoms found in the study group were heartburn and regurgitation; following surgical intervention, both of the these symptoms were relieved. Although relief of heartburn and regurgitation were noted, a significant increase in de novo dysphagia occurred. Dysphagia observed in the first 6-8 weeks after surgery is related to the operative technique and is a common finding. Investigations are necessary only if it maintains longer than this 6 to 8 week period. It also should be taken into account that subjective symptoms of dysphagia were proven not to correlate with manometric studies [21]. In this study, early postoperative dysphagia at 1-month follow-up was a significant finding but diminished at further observation points. It was proven that the results of pHmetric examination along with the results of $\mathrm{SI}$ and QOL questionnaires can predict the outcome of GERD patients [22].

Nissen fundoplication is a simple and effective approach for patients with gastroesophageal reflux symptoms due to diaphragmatic esophageal hiatal hernia - it should be the method of choice in patients with type III and IV hernia [23, 24]. What is more, it is the method of choice in the treatment of Barrett's esophagus in the cases of patients who were qualified for surgery [25].

Low-cost proton pump inhibitors (PPI) and laparoscopic Nissen fundoplication represent cost-effective treatment strategies. Procedural GERD therapy should be considered for patients who require highdose or expensive PPIs [26].
Quality of life in GERD patients is low, a fact which is confirmed by several authors [2]. Low quality of life was demonstrated using different instruments involving SF-36 or GERD-HRQL questionnaires [18]. In this study, global quality of life, measured with the FACIT-G questionnaire prior to the surgery, was on average $53.52 \%$ of the maximal value. In comparison, the score was $72 \%$ in conservatively treated patients with chronic pancreatitis who were examined in our center with the same questionnaire [21]. Scores from $48 \%$ to $81 \%$ were reported in different chronic diseases [27]. In this study significant improvement in global quality of life was observed as late as 12 months after surgery and remained at this level until the final observation point 24 months after surgery. Other authors reported significant improvement in quality of life as soon as 1 month after surgery [18, 28, 29]. More than $90 \%$ of the patients would undergo the surgery again or recommend it [30].

Rattner from Massachusetts Genral Hospital (MGH), using the Psychological and General Well Being Index (PGWB), presented improvement of global quality of life even sooner - at 2 weeks after surgery [31]. Considering GERD as a chronic disease, such late improvement in quality of life as that observed in our study after definitive treatment seems justified and likely from the psychological point of view. Patients suffering from long lasting GERD are well adapted to symptoms, limitations and problems related to the disease. Rapid or immediate improvement after anti-reflux surgery may result in invalidation of many, if not all defense and adaptive psychological mechanisms developed throughout the course of the disease. At the same time, new symptoms (e.g. de novo dysphagia, postoperative pain) create new psychological challenges. Thus it can be concluded that readaptation to the state of health takes 12 months in this study group. Such a long period of adjustment may appear in response to a fear of loss of secondary benefits, for instance increased social support (family and friends) and lack of a factor that perhaps justifies life's failures. This may factor into the explanation of why symptom relief in GERD patients does not immediately cause improvement in quality of life but rather is co-dependent on psychological re-adaptation to the new health condition.

Treatment satisfaction and quality of life evaluation could, apart from objective outcome measures, 
be incorporated in routine patient evaluation. Objective parameters often poorly describe patients' everyday functioning [32]. Moreover, 2 persons with the same pathology can respond completely differently to correction of the problem due to personality, coexisting depressive disorders and environmental or social factors [4, 33-35]. In this study, treatment satisfaction measured with the FACIT-TS-G questionnaire 1 month after surgery was high, reaching $78 \%$. This level was observed throughout the study, with fluctuations between $66.89 \%$ and $83.14 \%$. Satisfaction with the treatment was also measured using the GIQLI questionnaire (based on a single item). It was seen to increase from the first month after surgery, reaching significance ( $81 \%$ when converted to percentage of maximum values) 12 and 24 months following intervention. Similar satisfaction with laparoscopic treatment of GERD was observed by other authors [36, 37]. In a large study from MGH based on 405 patients operated on for GERD, $71 \%$ of the patients were satisfied with the surgical treatment [36]. Doctor-patient communication and interaction were proven to be of high importance for satisfaction of the patient with symptomatic treatment of GERD [38]. It can be anticipated that in surgical treatment of GERD a similar influence exists. Kamoltz proved that psychological intervention in some patients can result in significant improvement of quality of life and decrease symptom severity [4]. This fact confirms the observations of this study that relief of symptoms does not directly translate into improvement of global quality of life and suggests that surgery alone is an incomplete form of therapy.

For assessment of gastrointestinal quality of life the GIQLI questionnaire was used; it is the most commonly used instrument for measuring quality of life in gastrointestinal pathologies. The average score in the healthy population is $122.6 \pm 8.5$ points [11]. In this study group, the score was 82.15 points for preoperative assessment and is comparable with other authors [5]. Pointer et al. reported 87 points, Slim et al. reported 95.6 points, and Ciovica et al. reported 86 points [5].

Gastrointestinal quality of life, measured with the GIQLI questionnaire, significantly improved 3 months after surgery. This effect was sustained until the last observation point, that is, 24 months after surgical intervention. This result finds itself between symptom improvement on the DeMeester and Johnson GERD scale (at 1 month) and improvement in the general quality of life in FACIT-G assessment (at the twelfth month). Similarly, in a study by Dallemagne using the GIQLI questionnaire in GERD patients, postoperative improvement was observed in the total GIQLI score and the sub-scales gastrointestinal symptoms and emotional status [39]. In a report from Zell am See, improvement was recognized in the total GIQLI score and all sub-scales. The total GIQLI score after 3 months reached the level of the healthy population and remained at that level for the following 3 years of observation [38].

Efficiency and competency of follow-up procedures in this study can be considered a certain weakness of this study. However, it was performed with direct contact between doctor and patient, which by itself could improve patient satisfaction. Efficiency ranged from $89.42 \% 1$ month after surgery to $53.85 \%$ in the twenty-fourth month after surgery. In a study on quality of life after anti-reflux surgery, published by Woodcock et al., follow-up was executed at identical time intervals but by phone [3]. Subsequently, patients were sent questionnaires by mail and were asked to return the questionnaires, following completion, to the investigators. This methodology resulted in a lower response rate, from $40 \%$ to $65 \%$ at different time points.

In summary, GERD is a chronic disease of long duration, leading to impairment of quality of life. $\mathrm{Pa}$ tients, apart from typical symptoms of GERD, suffer from pain of significant severity. Surgical treatment - laparoscopic Nissen fundoplication - leads to improvement of quality of life, although not reaching healthy population levels. Symptom relief and quality of life improvement exhibit varying and individual dynamics (Figure 5). Relief from heartburn and regurgitation is observed 1 month after surgery and remains at that level throughout the 24-month observation period. Improvement of gastrointestinal quality of life is observed with a 3-month delay after the surgical procedure. Global quality of life improves significantly 12 months after surgery. Increasingly ameliorated quality of life was accompanied with high, constant satisfaction with treatment from the first month after surgery.

\section{Conclusions}

Quality of life is an important quality measure of surgery for GERD. Quality of life improvement is 


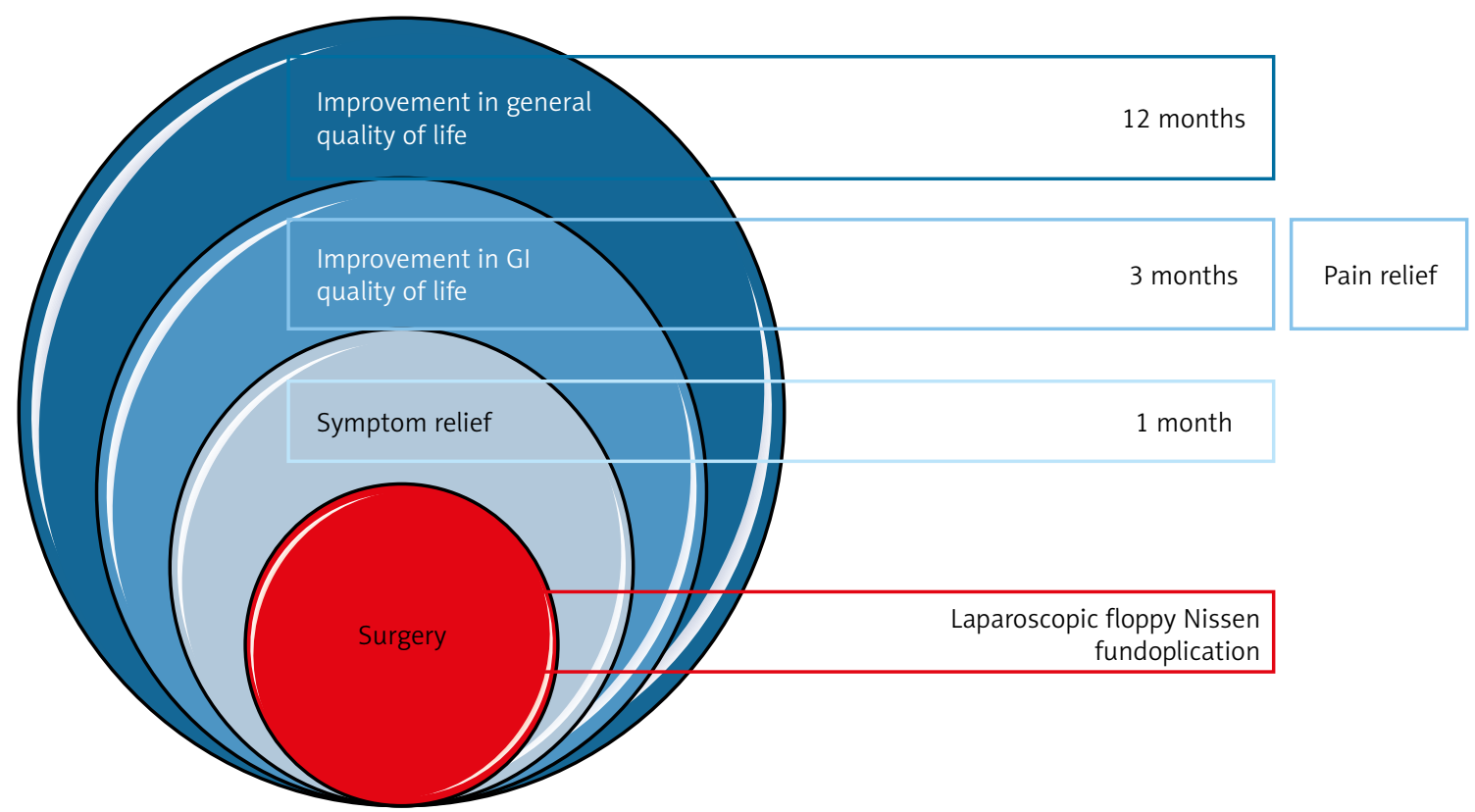

Figure 5. Schematic demonstration of dynamics of quality of life improvement (with pain and symptom relief) after laparoscopic floppy Nissen fundoplication

gradual, from GERD-specific symptoms to global quality of life. It is an important finding for the patients to ensure realistic expectations and for the doctors to develop an adequate follow-up schedule.

\section{Acknowledgments}

The authors would like to acknowledge Miss Anna Petropoulos for linguistic corrections.

\section{Conflict of interest}

The authors declare no conflict of interest.

\section{References}

1. Blomqvist A, Lonroth H, Dalenback J, Ruth M. Quality of life assessment after laparoscopic and open fundoplications. Scand J Gastroenterol 1996; 31: 1052-8.

2. Prasad M, Rentz AM, Revicki DA. The impact of treatment for gastro-oesophageal reflux disease on health related quality of life. Pharmacoeconomics 2003; 21: 769-90.

3. Woodcock SA, Watson DI, Lally C, et al. International Society for Disease of the Esophagus - Australasian Section. Quality of life following laparoscopic anterior 90 degrees versus Nissen fundoplication: results from a multicenter randomized trial. World J Surg 2006; 30: 1856-63.

4. Kamolz T, Granderath FA, Pointner R. Does major depression in patients with gastroesophageal reflux disease affect the outcome of laparoscopic antireflux surgery? Surg Endosc 2003; 17: 55-60.
5. Kalinowska E. Quality of life and personality disorders in patients after surgical treatment of esophageal reflux disease. Postępy Nauk Medycznych 2007; 10: 430-8.

6. Horvath KD, Jobe BA, Herron DM, et al. Laparoscopic Toupet fundoplication is an inadequate procedure for patients with severe reflux disease. J Gastrointest Surg 1999; 3: 583-91.

7. Neugebauer EAM, Sauerland S, Fingerhut A, et al. EAES guidelines for endoscopic surgery. Gastroesophageal reflux disease - update 2006. 125-142. Springer, Berlin Heidelberg 2006.

8. Stefanidis D, Hope WW, Kohn GP, et al. Guidelines for surgical treatment of gastroesophageal reflux disease. Practice/ Clinical Guidelines published online on: 02/2010 by the Society of American Gastrointestinal and Endoscopic Surgeons (SAGES).

9. Cella DF, Tulsky DS, Gray G, et al. The Functional Assessment of Cancer Therapy scale: development and validation of the general measure. J Clin Oncol 1993; 11: 570-9.

10. Webster K, Cella D, Yost K. The Functional Assessment of Chronic Illness Therapy (FACIT) Measurement System: properties, applications, and interpretation. Health Qual Life Outcomes 2003; 1: 79.

11. Eypasch E, Williams JI, Wood-Dauphinee S, et al. Gastrointestinal Quality of Life Index: development, validation and application of a new instrument. Br J Surg 1995; 82: 216-22.

12. DeMeester TR, Johnson LF, Kent AH. Evaluation of current operations for the prevention of gastroesophageal reflux. Ann Surg 1974; 180: 511-25.

13. Kelly AM. Setting the benchmark for research in the management of acute pain in emergency departments. Emerg Med (Fremantle) 2001; 13: 57-60.

14. Bunting DM, Szczebiot L, Peyser PM. Pain after laparoscopic antireflux surgery. Ann R Coll Surg Engl 2014; 96: 95-100. 
15. Buscher HC, Wilder-Smith OH, van Goor H. Chronic pancreatitis patients show hyperalgesia of central origin: a pilot study. Eur J Pain 2006; 10: 363-70.

16. Melzack R. Evolution of the neuromatrix theory of pain. Pain Pract 2005; 5: 85-94

17. DeMeester TR, Johnson LF, Joseph GJ, et al. Patterns of gastroesophageal reflux in health and disease. Ann Surg 1976; 184 : 459-70.

18. Granderath FA, Kamolz T, Schweiger UM, Pointner R. Long-term follow-up after laparoscopic refundoplication for failed antireflux surgery: quality of life, symptomatic outcome, and patient satisfaction. J Gastrointest Surg 2002; 6: 812-8.

19. Schneiderman N, Antoni MH, Saab PG, Ironson G. Health psychology: psychosocial and biobehavioral aspects of chronic disease management. Ann Rev Psychol 2001; 52: 555-80.

20. Kendall-Tackett K. The psychoneuroimmunology of chronic disease: exploring the links between inflammation, stress, and illness. American Psychological Association (APA); 1 edition, 2009.

21. Heider TR, Behrns KE, Koruda MJ, et al. Fundoplication improves disordered esophageal motility. J Gastrointest Surg 2003; 7: 159-63.

22. Rossetti G, Limongelli P, Cimmino M, et al. Outcome of medical and surgical therapy of GERD: predictive role of quality of life scores and instrumental evaluation. Int I Surg 2014; 12 Suppl 1: S112-6.

23. Piatkowski J, Jackowski M, Szeliga J. Laparoscopic surgery of esophageal hiatus hernia - single center experience. Videosurgery Miniinv 2014; 9: 13-7.

24. Migaczewski M, Grzesiak-Kuik A, Pędziwiatr M, Budzyński A Laparoscopic treatment of type III and IV hiatal hernia - authors' experience. Videosurgery Miniinv 2014; 9: 157-63.

25. Migaczewski M, Pędziwiatr M, Matłok M, Budzyński A. Laparoscopic Nissen fundoplication in the treatment of Barrett's esophagus - 10 years of experience. Videosurgery Miniinv 2013; 8: 139-45.

26. Funk LM, Zhang JY, Drosdeck JM, et al. Long-term cost-effectiveness of medical, endoscopic and surgical management of gastroesophageal reflux disease. Surgery 2015; 157: 126-36.

27. Muszalik M, Kedziora-Kornatowska K, Kornatowski T. Functional assessment and health-related quality of life (HRQOL) of elderly patients on the basis of the functional assessment of chronic illness therapy (FACIT)-F questionnaire. Arch Gerontol Geriatr 2009; 49: 404-8.

28. Kamolz T, Velanovich V. Quality of life in gastro-oesophageal reflux disease. Dig Liver Dis 2001; 33: 737-9.

29. Prieto-Díaz-Chávez E, Medina-Chávez JL, Brizuela-Araujo CA, et al. Patient satisfaction and quality of life following laparoscopic Nissen fundoplication. Rev Gastroenterol Mex 2014; 79: 73-8.

30. Prieto-Díaz-Chávez E, Medina-Chávez JL, Brizuela-Araujo CA, González-Jiménez MA et al. Patient satisfaction and quality of life following laparoscopic Nissen fundoplication. Rev Gastroenterol Mex 2014; 79: 73-8.

31. Rattner DW. Measuring improved quality of life after laparoscopic Nissen fundoplication. Surgery 2000; 127: 258-63.
32. Kreder HJ, Wright JG, McLeod R. Outcome studies in surgical research. Surgery 1997; 121: 223-5.

33. Stefaniak T, Makarewicz W, Kossakowska M, et al. Application of the FACIT questionnaire in the evaluation of the quality of life in patients with chronic pancreatitis: Polish conditions. Pol Przegl Chir 2003; 75: 956-65.

34. Guyatt GH, Feeny DH, Patrick DL. Measuring health related quality of life. Ann Intern Med 1993; 118: 622-9.

35. Velanovich V, Karmy-Jones R. Psychiatric disorders affect outcomes of antireflux operations for gastroesophageal reflux disease. Surg Endosc 2001; 15: 171-5.

36. Gee DW, Andreoli MT, Rattner DW. Measuring the effectiveness of laparoscopic antireflux surgery: long-term results. Arch Surg 2008; 143: 482-7.

37. Granderath FA, Kamolz T, Schweiger UM, Pointner R. Quality of life, surgical outcome, and patient satisfaction three years after laparoscopic Nissen fundoplication. World I Surg 2002; 26: 1234-8.

38. Bytzer P. What makes individuals with gastroesophageal reflux disease dissatisfied with their treatment? Clin Gastroenterol Hepatol 2009; 7: 816-22.

39. Dallemagne B, Weerts J, Markiewicz S, et al. Clinical results of laparoscopic fundoplication at ten years after surgery. Surg Endosc 2006; 20: 159-65.

Received: 23.12.2014, accepted: 9.03.2015. 